VAK 342

ББК 67.400

DOI 10.22394/1682-2358-2018-5-29-36

\author{
A.V. Dolzhikov, Candidate \\ of Sciences (Law), Docent of the Con- \\ stitutional Law Department, St. Peters- \\ burg State University

\section{THE EFFECT \\ OF THE \\ PROPORTIONALITY \\ PRINCIPLE \\ IN THE FIELD \\ OF CONSTITUTIONAL INSTITUTIONAL LAW}

The paper analyzes the effect of proportionality in the field of constitutional institutional law, i.e. rules on structures and powers of government. It is grounded that this constitutional principle is primarily a limitation of possible arbitrariness of public authority. Therefore, it is argued that the principle of proportionality cannot have the same application here as in the constitutional rights of individuals. Exceptions can be made when the relevant person or institution are vested with public legal rights with the possibility of their constitutional adjudication.

Key words and word-combinations: the principle of proportionality, constitutional justice, public law.
A.В. Аолжиков, кандидат юридиеских наук, доцент кафедрьг конституционного права Санкт-Петербургского государственного универcumema (email: a.dolzbiko»spbu.ru)

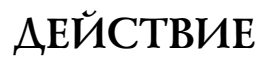 КОНСТИТУЩИОННОГО ПРИНЦИПА СОРАЗМЕРНОСТИ В СФЕРЕ ГОСУААРСТВЕННОГО ПРАВА*}

\begin{abstract}
Аннотаџия. Анализируется действие соразмерности в сфере государственного права (нормы о порядке формирования и компетенции органов публичной власти). Доказывается, что данный конституционный принцип является прежде всего средством ограничения возможного произвола публичной власти. Выдвигается аргумент, что в области государственного права принцип соразмерности не может иметь такое же применение, как в сфере конституционных прав частных лиц. Исключение составляют случаи, когда субъект наделяется публичными правами с возможностью их защиты в порядке конституционного судопроизводства.

Ключевые слова и словосочетания: принцип соразмерности, конституционное правосудие, государственное право.

B

Конститущии РФ можно выделить три ее главных структурных элемента: основы конституционного строя (глава первая), конституционные права (глава вторая) и государственное право (гмавы третья - вось-

* Статья подготовлена в рамках Совместной программы СПбГУ и DAAD «Амитрий Менделеев».
\end{abstract}


мая). Последнее понятие или условная категория «государственное организационное право» используется в настоящей публикаџии скорее Аля мингвистической экономии и означает совокупность конституционных норм, устанавцивающих порядок формирования и деятельности органов пубцичной власти.

На этом фоне теоретическое и прикладное значение приобретает проблема места принципа соразмерности в конституционной системе [1] . В этой системе соразмерность, обладая слишком абстрактным и открытым дия толкования содержанием, может использоваться в совершенно разных смыслах. Хорошо демонстрирует многоаспектность соразмерности рассуждения Г.А. Гаджиева, в котором родственное с соразмерностью понятие балансировки связывается со всеми основными элементами конституционной системы. Судья Конституционного Суда РФ, указывая на исторические предпосыики принятия Аействующего Основного Закона страны, подчеркивает, что «Конституция России принималась в 1993 году в условиях расколотого общества, ожесточенной борьбы сторонников прежнего режима и демократов. Поэтому она вся построена на балансировке. Это и баланс между конкурирующими вцастями (законоАательной, исполнительной и судебной), баланс межку конституционными принципами и между основными правами. Конституция отражает глубокие конфмикты межАу Аемократией и конституционализмом, межАУ свободой и порядком, межау индивидуаАьными правами и интересами государства, между принципом правового государства с его индивидуаАизмом и принципом соџиального государства с его идеей солидарности» [2, с. 51]. Отсюда можно заключить, что метод балансирования и принцип соразмерности находят выражение во всех трех базовых элементах конституционной системы. Наиболее противоречивым можно считать Аействие соразмерности в отношении госуАарственного права.

Конституционные предписания об организации публичной власти (главы 3-9 Конституции РФ), на первый взгляА, не касаются принципа соразмерности. Вместе с тем государственно-организационное право, будучи вкАюченным в текст Основного Закона, может мыслится не просто как набор компетентностных норм, но и в качестве среАства ограничения публичной власти посреАством четкого установления порядка формирования и осуществления деятельности органов.

Неоднозначно решается вопрос о применении принџипа соразмерности к вопросам разграничения компетенции межАу органами пубцичной вмасти. Российская правовая доктрина достаточно широко толкует содержание соразмерности и распространяет сферу действия этого принџипа на вопросы организаџии и осуществления компетенџии органов публичной вмасти. В первую очередь требование баланса интересов распространяется на федеративные отношения [3, с. 80-82] и разграничение полномочий в российской модели разделения властей [4]. Еще более универсальную позиџию занимает советник судьи Конституционного Суда РФ А.А. Ажагарян, считающий, что «принцип пропорџиональности, буАучи общеправовым, распространяется и на нормы права, имеющие компетенционный характер, т.е. на такие, которые устанавцивают и разграничивают предметы ведения и полномочия межАу разцичными уровнями и органами пубцичной вцасти» [5, с. 7-9]. 
Такие доктринальные подходы находят подтверждение в практике Конституџионного Суда РФ. В постановлении от 4 апремя 2002 г. № 8-П было подчеркнуто, что принятие федерального закона о роспуске регионального парламента «предполагает участие всех субъектов законодательного процесса, ориентировано на обеспечение необходимого баланса интересов Российской Федерации и ее субъектов и служит повышению степени защиты от произвольного и несоразмерного наступившим последствиям, а также нецелесообразного использования федерамьного воздействия. Именно в ходе законоАательной проџеАуры должна обсужАаться и гарантироваться соразмерность федерального воздействия негативным последствиям нарушения субъектом Российской Федерации конституционной обязанности смедовать Конституции Российской Федерации и федеральным законам. Обеспечение такой соразмерности - при наличии подтвержденных судебными решениями законодательно предусмотренных оснований - явмяется условием признания предусмотренных рассматриваемым Федеральным законом мер федерального воздействия соответствующими Конститущии Российской Федерации» [6] .

Отсюда можно заключить, что требования баланса интересов и в целом принцип соразмерности выступают критериями конституџионности мер федерального вмешательства в полномочия региональных властей. Кончено, саму идею согласования компетенџии центральных и региональных органов власти нельзя отрицать. ОАнако использование Аля этих цемей такого же термина, что и в сфере конституционных прав, не может не вызывать трудности. ПоАобный подход по сути позволяет приравнивать горизонтальные отношения однопорядковых субъектов (например, пармамента и правительства) к взаимодействиям частного миџа с публичной властью, которые характеризуются вертикальными связями и подчинением. С практической точки зрения в обмасти конституционных прав и государственного права должны действовать разные правовые режимы и разная проџедура обжалования случаев несоблюАения конституционного принципа соразмерности. Чтобы избежать смешения в понятии соразмерности Авух совершенно разных способов регулирования, по крайней мере в отношении государственного, следует использовать Аругую терминологию.

На этом фоне интересны подходы к проблеме распространения сферы Аействия принципа соразмерности на обцасть государственного права в зарубежном конститущионализме. Прямо противопоможное мнение было сформумировано в немеџкой правовой доктрине, где сфера действия соразмерности по общему правилу не охватывает государственное право. Так, председатель Федерального Конституционного Суда ФРГ А. Фосскуле особо подчеркивает, что «в области государственного организационного права, а также местного самоуправления принщип соразмерности, согласно не вполне бесспорной позиции Федерального конституционного суда Германии, неприменим» [7, с. 161] . Здесь выявляется разниџа в использовании данного принџипа в отношении государственной вмасти и местного самоуправления. Следует обратить внимание и на то, что даже по оџенке руководителя этого суда такая позиџия не мишена недостатков. 
Аостаточно ясно упомянутый подход быц выражен в решении Федерального конституционного суда Германии от 22 мая 1990 г., согласно которому «вытекающие из принџипа правового государства ограничения действий государства в сфере правового статуса индивидов, не применимы к правовым отношениям между федераџией и землями по разграничению их компетенции. Это в особенности действительно Амя принципа соразмерности, которому принадмежит функция охраны сферы индивидуальных прав и свобод... Поэтому в особенности связанное с ним учение о категориях «сфера свободы» и «вмешательства» не могут быть перенесены ни на конкретную сферу компетенџии земель, следующую из ее конкуренџии с федераџией, ни на вопросы разграничения компетенции в общем» [8, с. 310, 338]. Фактически в данном решении указывается на недопустимость по аналогии применять конститущионный принщип соразмерности, направленный на защиту индивидуальной свободы, к вопросам государственного права. Несмотря на теоретические споры [9], в итоге «применение принџипа пропорџиональности было отвергнуто также в Аругих сферах, где конфликтуют Аруг с Аругом Ава публичных интереса, не затрагивая индивидуальную сферу свободы» $[10$, c. 52]. Например, Федеральный конституционный суд считает недопустимым распространять действие принципа соразмерности на вопросы превышения размера кредитов или иных финансовых обязательств (абз. 1 ст. 115 Основного закона ФРГ). Это было аргументировано тем, что обе конфликтующие в деле ценности (кредитные мимиты на сумму капитальных затрат и противодействие нарушения национального экономического баланса) представляют собой публичные интересы, направленные на достижения общего бкага [11, с. 313, 341] . Смедовательно, конститущионный принщип соразмерности не применим к ситуаџии конфликта двух публичных ценностей, если такой конфликт не затрагивает конституционные права частных киџ.

Вместе с тем Федеральный конституционный суд Германии распространяет действия принџипа соразмерности на вопросы местного самоуправмения. В соответствии с решением от 24 июня 1969 г. «законы, которые ограничивают коммунальные полномочия, должны соблюдать соразмерность права местных сообществ на муниципальное самоуправление» $[12$, с. 228, 242]. Такое исключение можно объяснить тем, что местное самоуправление рассматривается в таких ситуациях не как один из уровней пубцичной власти, но в качестве особого субъективного пубцичного права с возможным использованием дмя его защиты коммунальной конститущионной жалобы [13] .

В связи с этим можно обратить внимание на схожие походы к распространению соразмерности в муниґипальном праве России, где этот принґип связывается с общими вопросами понимания местного самоуправления [14]. В качестве одного из главных методологических подходов Конститущионного Суда РФ в организаџии государственной и муниџипальной власти судья Н.С. Бондарь называет «принщип баланса централизации и децентрализации, требующий установления Амя кажАой сферы общественных отношений разумной меры пубцично-властного воздействия и саморегулирования» $[14$, с. 6]. В работе советника судьи Конституџионного Суда РФ А.А. Ажагаряна принщип соразмерности 
анализируется в качестве проблемы разграничения законодательных полномочий по регулированию местного самоуправления между федеральным, региональным и муниципацьным уровнями пубцичной вмасти. В таком изцожении содержкание данной работы скорее посвящено принџипу субсидиарности, который также имеет широкое применение в сфере местного самоуправления [5]. Кроме общих работ, принщип соразмерности и требование баланса интересов исследуются применительно к финансово-экономическим гарантиям местного самоуправления [15] .

Вслед за российской доктриной использует принщип соразмерности в сфере местного самоуправления и Конституционный СуА РФ. В постановлении от 30 ноября 2000 г. № 15-П подчеркивается, что «произвольный характер госуАарственного контроля за деятельностью органов местного самоуправления... позволяет контролирующему органу самому определять степень соразмерности такого вмешательства значимости охраняемых интересов, при том что... установцен неопределенный круг органов государственной вцасти и Аолжнос-

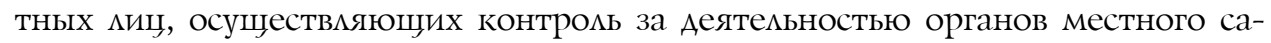
моуправления. Подобная интерпретация... противоречит конституционному определению пределов и способов контроля государства за деятельностью органов местного самоуправления и в силу этого не соответствует... Конституции Российской Федерации» [16]. Тем самым в конституционном судопроизводстве соразмерность служит критерием оџенки вмешательства государственных органов в осуществление конституционного права на местное самоуправление. Понимание местного самоуправления именно в таком качестве явцяется принципиальным А^я расширения действия конституционного принџипа на эту обцасть отношений.

В отмичие от пубцичной власти местное самоуправление бымо признано в практике Конституџионного Суда РФ в качестве особого неписаного конституционного права [17]. Хотя Аця нормативного обоснования используются статьи, находящиеся в главе восьмой Конституции РФ (ч. 2 ст. 130, ст. 131), важным последствием такого подхода выступает распространение на это право тех гарантий, которые закреплены в главе второй Конституции РФ. Несмотря на отсутствие такого права в главе первой Конституџии РФ, страж отечественного Основного Закона отреагировам на обнаружившиеся угрозы конституционной ценности местного самоуправление со стороны феАерального и регионального законодателей, используя цогику конституционных прав. Например, в так называемом курском деле было отмечено, что возможность передачи органам государственной власти полномочий по решению вопросов местного значения в мюбом объеме может «ограничить вопреки требованиям статьи 55 (часть 3) Конституции Российской Федерации право граждан на осуществление местного самоуправления» [16]. Относящаяся к числу таких требований соразмерность выполняет Аля конституционного права на местное самоуправление ту же защитную функщию, что и в отношении иных конституционны прав.

Подход Конституџионного Суда РФ по применению соразмерности к местному самоуправлению можно считать проявлением идеологии судейского ак- 
тивизма. В его практике конституционное право на местное самоуправление несмотря на неписаный характер считается ценностью, которая соизмерима по отношению конституционным правам, получившим непосредственное закрепления в главе второй Конституции РФ. Такой вывод вытекает из правовой позиции Конституџионного Суда РФ, который осуществляет проверку «баманса межАу такими конституционно защищаемыми ценностями, как права

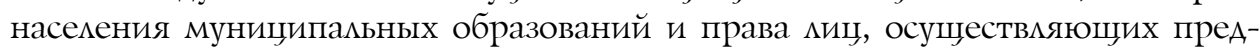
принимательскую деятельность» [18] .

В целом случаи распространения действия конституционного принципа соразмерности на вопросы государственного права можно именовать гуманитарным подходом. В таких делах субъекты федерации или местные сообщества рассматриваются в качестве неких комлективных носителей конститущионных прав. В отношении местного самоуправления гуманитарный подхоА может быть оправдан, веАь Конституционный СуА РФ оАновременно признал местные сообщества носителем права на конститущионную жалобу в порядке ч. 4 ст. 125 Конституции РФ и п. 3 ч. 1 ст. 3 Федерального конституционного закона «О Конституционном Суде РФ». С учетом взаимосвязи таких проџессуальных и материальных аспектов действия соразмерности распространять этот принџип на вопросы разграничения компетенџии органов пубцичной власти было бы ошибочным. Сегодня подобные гуманитарные подходы в конституционном судопроизводстве имеют скорее теоретический характер с учетом фактической трансформации России в централизованную федерацию, а также частичного возврата советской модели местного управления.

Подобный вывод не Аолжен отрицать значения самой идеи баланса интересов в области государственного права. ОАнако в конституционном судопроизводстве использование одного термина к совершенно разным по природе элементам конституционной системы требует уточнения. Основная функция соразмерности состоит в оценке преследующих пубцичные цели вмешательств в конституџионные права, олицетворяющих частный интерес. В сфере же госуАарственного права взвешивать приходится отношения двух вмастных субъектов. Соответственно, с обеих сторон данного отношения будут публичные интересы (например, интересы парламента и интересы правительства).

При этом толкование и применение Конституционным Судом РФ принџипа соразмерности в области конституџионных прав, безусловно, учитывает неравенство отношений индивида с государством. В них индивиА выступает изначально уязвимым субъектом. Именно поэтому в конституционном судопроизводстве применяются правовые средства, соответствующие такому уязвимому статусу инаивиду. Эти среАства по аналогии с принџипом трудового права можно обозначить категорией «in favorem» (кат. - в пользу). Наиболее очевидным примером таких правовых средств будут признаваемые в отечественном конституционном судебном проџессе презумпщии, улучшающие процессуальное положение индивида как стороны процесса. Это же будет касаться более выгодного положения индивида в распределении бремени доказывания вопросов нарушения принципа соразмерности и т.п. Поэтому вряА $\Lambda и$ верно применять правовые позиции Конституционного Суда РФ по вопросам защи-

34 Bulletin of the Volga Region Institute of Administration • 2018. Vol. 18. № 5 
ты конституционных прав, вкцючая толкование принципа соразмерности, к государственно-вцастным отношениям (споры между государственными органами, разграничение компетенции федерации с ее субъектами, споры межАу органами местного самоуправцения и органами государственной вцасти). По крайней мере, применимость правовых позиций Конституционного Суда РФ о принципе соразмерности в области конституционных прав не Аолжна автоматически переноситься на сферу государственного права.

Таким образом, в области государственного права соразмерность будет иметь ограниченное применение. ЗАесь скорее Аолжна Аействовать похожая концепция сдержек и противовесов, но не метод судейского взвешивания. В противном случае использование гуманитарного по своей природе инструментария походит на меры соџиальной помощи дия руководителя государственной корпорации, получающего многомимиионные бонусы и имеющего и так Аостаточное число иных привилегий. Соразмерность Аолжна использоваться здесь в качестве вспомогательного механизма, когда Аругие юридические средства разрешения споров о компетенции оказываются неэффективными и мишь при условии признания субъективных публичных прав за публичными образованиями, как в случае с конституционным правом на местное самоуправление. В терминологическом пиане дия области разграничения компетенции органов пубцичной вцасти можно использовать принџип субсидиарности из федерализма и доктрину противовесов, явцяющуюся частью конституционного принџипа разделения властей, мибо позаимствовать дмя этих цемей понятие компромисса из политической науки.

\section{Библиографический список}

1. Кононов К.А. Система отрасли конституционного права: историко-теоретический очерк. СПб., 2011.

2. Гаджиев Г.А. Об особенностях толкования Конституции в Российской Федерации // Актуальные проблемы теории и практики конституционного судопроизводства / под ред. В.Н. Демидова [и др.]. Казань, 2012. Вып. 7. С. 51-58.

3. Железнов Б.Л. Федерализм - это баланс интересов // Актуальные проблемы юридической науки и образования на современном этапе. Казань, 2003. С. 80-82.

4. Авакьян C.A. О возможных и конституционно-легитимных путях изменения баланса властей в Российской Федерации // Конституционное и муниципальное право. 2008. № 3. C. 2-6.

5. Джагарян А.А. Принцип пропорциональности как основа разграничения регулятивных полномочий между уровнями власти в сфере местного самоуправления (на основе практики Конституционного Суда Российской Федерации) // Муниципальная служба: правовые вопросы. 2013. № 1. С. 7-9.

6. По делу о проверке конституционности отдельных положений Федерального закона «Об общих принципах организации законодательных (представительных) и исполнительных органов государственной власти субъектов Российской Федерации» в связи с запросами государственного собрания (Ил Тумэн) Республики Саха (Якутия) и Совета Республики Государственного Совета - Хасэ Республики Адыгея: постановление Конституционного Суда РФ от 4 апр. 2002 г. № 8-П // С3 РФ. 2002. № 15. Ст. 1497.

7. Фосскуле А. Принцип соразмерности // Сравнительное конституционное обозрение. 2015. № 1. C. 159-163. 
8. Urteil des Zweiten Senats vom 22. Mai 1990, 2 BvG 1/88 [Kalkar II] // Entscheidungen des Bundesverfassungsgerichts. Bd. 81.

9. Frenz W. Gemeindliche Selbstverwaltungsgarantie und VerhдltnismдЯigkeit // Die Verwaltung. 1995. Bd. 28. H. 1. S. 33-63.

10. Косh O. Der Grundsatz der VerhдltnismдЯigkeit in der Rechtsprechung des Gerichtshofs der Europдischen Gemeinschaften. Berlin, 2003.

11. Urteil des Zweiten Senats vom 18. April 1989, 2 BvF 1/82 [Staatsverschuldung] // Entscheidungen des Bundesverfassungsgerichts. Bd. 79.

12. BeschluЯ des Zweiten Senats vom 24. Juni 1969, 2 BvR 446/64 [Sorsum] // Entscheidungen des Bundesverfassungsgerichts. Bd. 26.

13. Гриценко E.B., Вилл Р. Защита прав местного самоуправления средствами конституционного правосудия в России и Германии // Журнал конституционного правосудия. 2015. № 4. C. $22-38$.

14. Бондарь Н.С. Местное самоуправление и конституционное правосудие: конституционализация муниципальной демократии в России. М., 2009.

15. Деменкова А.В. Реализация принципа соразмерности местных финансов объему компетенции органов местного самоуправления // Гражданин и право. 2006. № 4. С. 62-71.

16. По делу о проверке конституционности отдельных положений Устава (Основного Закона) Курской области в редакции Закона Курской области от 22 марта 1999 г. «О внесении изменений и дополнений в Устав (Основной Закон) Курской области»: постановление Конституционного Суда РФ от 30 нояб. 2000 г. № 15-П // СЗ РФ. 2000. № 50. Ст. 4943.

17. Еремин А.P. Реализация права человека и гражданина на местное самоуправление в Российской Федерации: конституционные вопросы. Саратов, 2003.

18. По делу о проверке конституционности положений части 4 статьи 31, пункта 6 части 1 статьи 33 и статьи 37 Федерального закона «О государственной гражданской службе Российской Федерации» в связи с жалобой гражданки В.Ю. Боровик: постановление Конституционного Суда РФ от 20 дек. 2010 г. № 22-П // СЗ РФ. 2011. № 1. Ст. 264. 